Published in final edited form as:

J Am Chem Soc. 2018 August 15; 140(32): 10363-10367. doi:10.1021/jacs.8b06527.

\title{
Ligand-Enabled $\beta-\mathrm{C}\left(\mathrm{sp}^{3}\right)-\mathrm{H}$ Olefination of Free Carboxylic Acids
}

\author{
Zhe Zhuang ${ }^{\dagger}$, Chang-Bin $\mathrm{Yu}^{\dagger}$, Gang Chen ${ }^{\dagger}$, Qing-Feng Wu ${ }^{\dagger}$, Yi Hsiao ${ }^{\ddagger}$, Candice L. Joe ${ }^{\ddagger}$, \\ Jennifer X. Qiao§, Michael A. Poss $\$$, and Jin-Quan Yu ${ }^{\dagger}$ \\ † Department of Chemistry, The Scripps Research Institute, 10550 N. Torrey Pines Road, La \\ Jolla, California 92037 \\ ‡ Chemical and Synthetic Development, Bristol-Myers Squibb, 1 Squibb Drive, New Brunswick, \\ New Jersey 08903 \\ $\S$ Discovery Chemistry, Bristol-Myers Squibb Company, PO Box 4000, Princeton, New Jersey \\ 08543
}

\begin{abstract}
An acetyl-protected aminoethyl phenyl thioether has been developed to promote $\mathrm{C}\left(\mathrm{sp}^{3}\right)-\mathrm{H}$ activation. Significant ligand enhancement is demonstrated by the realization of the first $\mathrm{Pd}(\mathrm{II})$ catalyzed olefination of $\mathrm{C}\left(\mathrm{sp}^{3}\right)-\mathrm{H}$ bonds of free carboxylic acids without using an auxiliary. Subsequent lactonization of the olefinated product via 1,4 addition provided exclusively monoselectivity in the presence of multiple $\beta$-C-H bonds. The product $\gamma$-lactone can be readily opened to give either the highly valuable $\beta$-olefinated or $\gamma$-hydroxylated aliphatic acids. Considering the challenges in developing Heck couplings using alkyl halides, this reaction offers a useful alternative.
\end{abstract}

\section{Graphical Abstract}

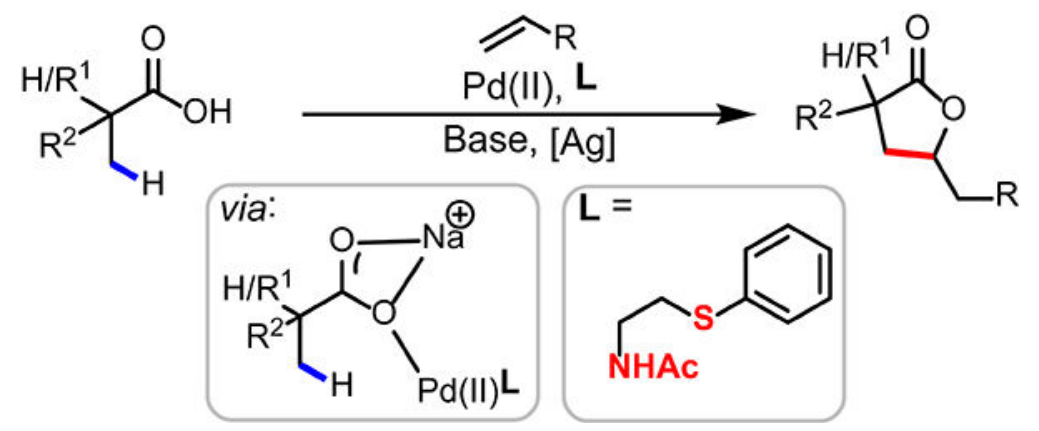

Carboxylic acids are readily available and highly versatile starting materials in organic synthesis. In the past decade, a number of directed $\mathrm{C}\left(\mathrm{sp}^{3}\right)-\mathrm{H}$ activation reactions of aliphatic acids using various directing groups have provided unprecedented synthetic disconnections. ${ }^{1}$ For example, Pd-catalyzed $\mathrm{C}\left(\mathrm{sp}^{3}\right)-\mathrm{H}$ iodination ${ }^{1 \mathrm{a}}$, oxygenation, ${ }^{1 \mathrm{~b}}$ arylation, ${ }^{\mathrm{c}}$ alkylation, ${ }^{1 \mathrm{~d}-\mathrm{f}}$ and fluorination ${ }^{1 \mathrm{~g}, 1 \mathrm{~h}}$ have been developed using various directing auxiliaries. However,

Supporting Information Available: Experimental procedures and spectral data for all new compounds (PDF). This material is available free of charge via the Internet at http://pubs.acs.org. 
carboxyl-directed $\mathrm{C}\left(\mathrm{sp}^{3}\right)-\mathrm{H}$ activation reactions are rare. $\mathrm{K}_{2} \mathrm{PtCl}_{4}$-catalyzed or mediated carboxyl-directed lactonization of aromatic and aliphatic acids has been demonstrated, albeit in poor yields. ${ }^{2}$ The use of COOK salts led to the discovery of Pd-catalyzed $\mathrm{C}\left(\mathrm{sp}^{3}\right)-\mathrm{H}$ arylation of free carboxylic acids ${ }^{3}$ and was further improved by ligand acceleration (eq 1). 4, 5 However, further development of carboxyl-directed $\mathrm{C}\left(\mathrm{sp}^{3}\right)-\mathrm{H}$ functionalization reactions have only been successful using exogenous auxiliaries. In particular, the development of a $\mathrm{C}\left(\mathrm{sp}^{3}\right)-\mathrm{H}$ olefination reaction protocol would be synthetically useful considering the challenges of developing Heck couplings with alkyl halides due to premature $\beta$-hydride elimination. ${ }^{6}$ To date, only three precedents using auxiliaries have been reported. ${ }^{7}$ These reactions suffer from the undesired subsequent cyclization reaction with the nitrogen containing auxiliary, preventing further synthetic elaborations.
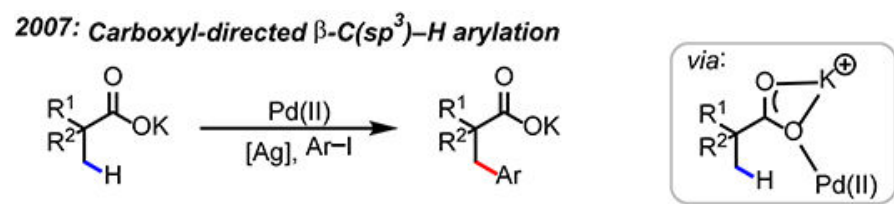

This work: Carboxyl-directed $\beta-C\left(s p^{3}\right)-H$ olefination
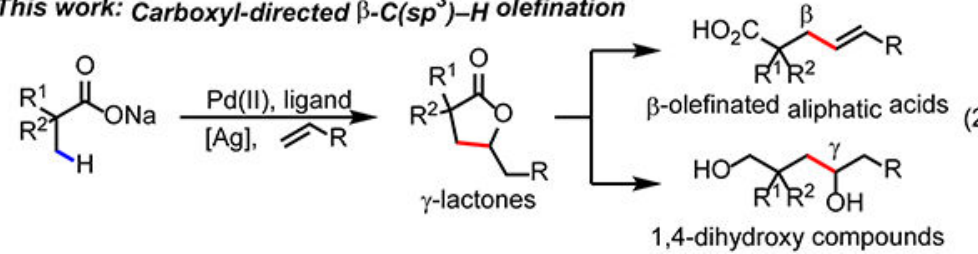

Herein we report the first example of $\beta$ - $\mathrm{C}\left(\mathrm{sp}^{3}\right)-\mathrm{H}$ olefination of free carboxylic acids enabled by an acetyl-protected aminoethyl phenyl thioether ligand (eq 2). Carboxylic acids containing a-hydrogens are also compatible with this catalyst. The $\gamma$-lactone products formed by $\mathrm{C}\left(\mathrm{sp}^{3}\right)-\mathrm{H}$ olefination and subsequent 1,4-addition can be found in many bioactive compounds (Figure 1). ${ }^{8}$ The hydrolytic opening of the lactones provides synthetically useful $\beta$-olefinated aliphatic acids or 1,4-dihydroxy compounds (eq 2).

Our initial investigation into carboxyl-directed $\beta$-C $\left(\mathrm{sp}^{3}\right)-\mathrm{H}$ olefination employed 2,2dimethylbutyric acid $\mathbf{1 b}$ as a model substrate and benzyl acrylate $\mathbf{2 a}$ as an olefin coupling partner. We have previously established that countercations, such as $\mathrm{Na}^{+}$or $\mathrm{K}^{+}$, promote $\mathrm{Pd}(\mathrm{II})$ insertion into ortho- or $\beta$-C-H in carboxylic acid substrates by engaging $\mathrm{K}^{2}$ coordination with the carboxylate. ${ }^{5}$ We were pleased to observe that using $\mathrm{Pd}(\mathrm{OAc})_{2}(10$ mol\%) in the presence of $\mathrm{Na}_{2} \mathrm{HPO}_{4} \cdot 7 \mathrm{H}_{2} \mathrm{O}$ as the base and $\mathrm{Ag}_{2} \mathrm{CO}_{3}$ as the oxidant provided olefination product $\mathbf{3 b}$ in $16 \%$ yield (Table 1 ). We next tested representative pyridine- or quinoline-based ligands (L1-L4) developed in our laboratory to exploite ligand acceleration. To our delight, the yield was improved to $57 \%$ by using the simple monodentate 2,6-lutidine ligand L2. Further screening of pyridone ligands (L5-L7) which were identified to enable meta- $\mathrm{C}\left(\mathrm{sp}^{2}\right)-\mathrm{H}$ arylation of phenyl acetic acids ${ }^{5 \mathrm{e}}$ only gave inferior yields. After extensive screening of different bases and external oxidants, the product $\mathbf{3 b}$ could be isolated in $70 \%$ when we used $\mathrm{K}_{2} \mathrm{HPO}_{4}$ as the base and $\mathrm{AgOAc}$ as the oxidant in the presence of 2,6-lutidine L2 $(15 \mathrm{~mol} \%)$. However, use of this ligand is limited to carboxylic acids a-containing quaternary centers. 
To overcome this limitation, we turned our attention to the bidentate ligands that were recently developed to accelerate $\mathrm{C}\left(\mathrm{sp}^{3}\right)-\mathrm{H}$ activation in our laboratory. Guided by ligandaccelerated ortho- $\mathrm{C}\left(\mathrm{sp}^{2}\right)-\mathrm{H}$ olefination of phenyl acetic acids ${ }^{5 \mathrm{c}}$ and $\beta-\mathrm{C}\left(\mathrm{sp}^{3}\right)-\mathrm{H}$ arylation of $a$-branched carboxylic acids, ${ }^{4 \mathrm{~d}, 4 \mathrm{e}}$ we tested mono- $N$-protected amino acid (MPAA) ligands. However, this type of ligand gave poor yields. Other bidentate ligands (L11-L13), previously found to promote enantioselective intermolecular $\mathrm{C}\left(\mathrm{sp}^{3}\right)-\mathrm{H}$ activation, ${ }^{4 \mathrm{a}, 4 \mathrm{~b}}$ gave moderate yield with substrate $\mathbf{1 b}$, but displayed no reactivity with a-hydrogen containing carboxylic acids. The essential role played by the NHAc group in the bidentate ligands (L8L13) prompted us to replace the quinoline and oxazoline by sulfur as a soft $\sigma$-donor. ${ }^{9} \mathrm{We}$ prepared acetyl-protected aminoethyl phenyl thioether ligand L14 in two steps from commercial available 2-aminoethyl bromide. Ligand L14 afforded a dramatic increase in reactivity providing a $90 \%$ yield. The product could be isolated in nearly quantitative yield $(96 \%)$ by increasing the temperature and using $\mathrm{Pd}(\mathrm{TFA})_{2}$. L14, a bench-stable and odorless solid, was easily recycled after the reaction, demonstrating its stability in the presence of a mild oxidant (Ag salt in this case). Efforts to introduce substitution on the ligand backbone (L15) did not enhance the reactivity. It is worth-noting that the formation of the $\gamma$-lactone via the intramolecular conjugate addition secured the exclusive mono-selectivity which has not been possible in other $\mathrm{C}-\mathrm{H}$ functionalizations in the presence of multiple $\beta$-C-H bonds.

With the optimal ligand and reaction conditions in hand, the scope of aliphatic carboxylic acid substrates was evaluated (Table 2). For aliphatic acids bearing a-quaternary centers, both 2,6-lutidine $\mathbf{L 2}$ and the thioether ligand $\mathbf{L 1 4}$ are effective with the latter being superior (3a-3h). Various a-dialkyl substituted propionic acids were olefinated to give the desired $\gamma$ lactones in good to excellent yields (3a-3d). Phenyl groups at the $\beta$ - or $\gamma$-positions of the carboxyl group were well tolerated $(\mathbf{3 e}, \mathbf{3 f}$, and $\mathbf{3 m})$ and remained intact despite the potentially reactive ortho- $\mathrm{C}\left(\mathrm{sp}^{2}\right)-\mathrm{H}$ bonds. Substrates containing a coordinative heteroatom such as oxygen $(\mathbf{1 g}, \mathbf{1 h}, \mathbf{1 s}$, and $\mathbf{1 x})$ or nitrogen (1p) were also compatible with the $\beta$ $\mathrm{C}\left(\mathrm{sp}^{3}\right)-\mathrm{H}$ olefination conditions. Gemfibrozil (1g), which is an oral drug used to lower lipid levels, ${ }^{10}$ was converted to the corresponding $\gamma$-lactone $\mathbf{3 g}$ in $81 \%$ yield. The use of the newly developed ligand $\mathbf{L 1 4}$ has rendered a broad range of a-hydrogen containing carboxylic acids $(\mathbf{1 i}-\mathbf{1 q})$ reactive under the standard conditions. These substrates are typically challenging due to the lack of a favorable Thorpe-Ingold effect as well as the interfering acidic a-C-H bond. The olefination of $N$-phthaloyl alanine substrate $1 \mathbf{p}$ is particularly interesting considering the importance of $a$-amino lactones. This protocol was also successfully extended to the olefination of cyclopropyl and cyclobutyl $\mathrm{C}-\mathrm{H}$ bonds (3q-3x), affording highly strained fused bicyclic lactones. The presence of hydroxyl (3s) and halogen (3t) groups in those lactones offers a synthetic handle for further elaboration.

We next evaluated the scope of the olefin coupling partners by using pivalic acid 1a as the pilot acid substrate (Table 3). The olefination with various acrylate derivatives proceeded in excellent yields $(\mathbf{4 a}-\mathbf{4 c})$. Other electron-withdrawing groups attached to the olefins including amide (2d), ketone (2e), nitrile (2f), sulfone (2g), and phosphonate (2h), were all compatible with the olefination conditions, providing the desired $\gamma$-lactones in excellent yields. $N$-aryl or alkyl maleimides (2i-2k) were also found to be suitable coupling partners 
under the optimized conditions, providing diverse spirocyclic pyrrolidines in moderate to excellent yields.

Coupling of an alkyl fragment with an olefin is highly valuable due to the lack of success of analogous Heck couplings. To demonstrate the synthetic utility of these $\mathrm{C}\left(\mathrm{sp}^{3}\right)-\mathrm{H}$ olefination products, we performed the olefination of pivalic acid 1a with benzyl acrylate $\mathbf{2 a}$ on gram scale to obtain the $\gamma$-lactone 3a in 93\% isolated yield (Scheme 1). The $\gamma$-lactone was then successfully transformed into three structurally distinct synthons: (1) selective hydrolysis of the ester under the acidic conditions gave the $\gamma$-lactone $\mathbf{5 a}$ which can be further elaborated to other compounds by decarboxylative coupling $;{ }^{11}$ (2) hydrolysis in the presence of sodium hydroxide generated adipic acid derivative $\mathbf{5 b}$ which is widely used in the polymer chemistry industry; (3) reduction of the lactone and ester afforded the 1,4,6-triol 5c.

In conclusion, we have developed a new thioether based bidentate ligand L14 that effectively promotes $\beta$-C $\left(\mathrm{sp}^{3}\right)-\mathrm{H}$ olefination of a broad range of free carboxylic acids. The unique synthetic utility of olefination is demonstrated by the synthesis of $\gamma$-lactones, $\beta$ vinylated acids, and $\gamma$-hydroxylated acids, which has not been possible using an auxiliary approach. This transformation provides a highly desirable synthetic disconnection considering the challenges in developing analogous Heck couplings due to premature $\beta$ hydride elimination.

\section{Acknowledgements.}

We gratefully acknowledge The Scripps Research Institute and Bristol-Myers Squibb for financial support. This work was supported by NIH (NIGMS, 2R01 GM084019).

\section{References}

(1). (a) Giri R; Chen X; Yu J-Q Angew. Chem., Int. Ed 2005, 44, 2112.(b) Giri R; Liang J; Lei J-G; Li J-J; Wang D-H; Chen X; Naggar IC; Guo C; Foxman BM; Yu J-Q Angew. Chem., Int. Ed 2005, 44, 7420.(c) Zaitsev VG; Shabashov D; Daugulis O J. Am. Chem. Soc 2005, 127, 13154. [PubMed: 16173737] (d) Zhu R-Y; He J; Yu J-Q J. Am. Chem. Soc 2014, 136, 13194. [PubMed: 25208210] (e) Tran LD; Daugulis O Angew. Chem., Int. Ed 2012, 51, 5188.(f) Zhang S-Y; Li Q; He G; Nack WA; Chen G J. Am. Chem. Soc 2013, 135, 12135. [PubMed: 23919290] (g) Zhu RY; Tanaka K; Li G-C; He J; Fu H-Y; Li S-H; Yu J-Q J. Am. Chem. Soc 2015, 137, 7067. [PubMed: 26001406] (h) Zhang Q; Yin X-S; Chen K; Zhang S-Q; Shi B-F J. Am. Chem. Soc 2015, 137, 8219. [PubMed: 26067591]

2). (a) Kao L-C; Sen A J. Chem. Soc., Chem. Commun 1991, 1242.(b) Dangel BD; Johnson JA; Sames D J. Am. Chem. Soc 2001, 123, 8149. [PubMed: 11506585]

3). Giri R; Maugel N; Li J-J; Wang D-H; Breazzano SP; Saunder LB; Yu J-QJ Am. Chem. Soc 2007, $129,3510$.

4. (a) Chen G; Gong W; Zhuang Z; Andra MS; Chen Y-Q; Hong X; Yang Y-F; Liu T; Houk KN; Yu JQ Science 2016, 353, 1023. [PubMed: 27701111] (b) Wu Q-F; Shen P-X; He J; Wang X-B; Zhang F; Shao Q; Zhu R-Y; Mapelli C; Qiao JX; Poss MA; Yu J-Q Science 2017, 355, 499. [PubMed: 28154075] (c) Chen G; Zhuang Z; Li G-C; Saint-Denis TG; Hsiao Y; Joe CL; Yu J-Q Angew. Chem., Int. Ed 2017, 56, 1506.(d) Zhu Y; Chen X; Yuan C; Li G; Zhang J; Zhao Y Nat. Commun 2017, 8, 14904. [PubMed: 28383026] (e) Ghosh KK; van Gemmeren M Chem. -Eur. J 2017, 23 , 17697. [PubMed: 29148233]

5. (a) For COONa or COOK directed diverse $\mathrm{C}(\mathrm{sp} 2)-\mathrm{H}$ activation reactions, see: Mei T-S; Giri R; Maugel N; Yu J-Q Angew. Chem., Int. Ed 2008, 47, 5215.(b) Giri R; Yu J-Q J. Am. Chem. Soc 
2008, 130, 14082. [PubMed: 18834125] (c) Wang D-H; Engle KM; Shi B-F; Yu J-Q Science 2010, 327, 315. [PubMed: 19965380] (d) Cheng G; Li T-J; Yu J-Q J. Am. Chem. Soc 2015, 137, 10950. [PubMed: 26274062] (e) Li G-C; Wang P; Farmer ME; Yu J-Q Angew. Chem., Int. Ed 2017, 56, 6874.

6. (a) For rare examples of Heck-type coupling of alkyl iodides and alkenes, see: Firmansjah L; Fu GC J. Am. Chem. Soc 2007, 129, 11340. [PubMed: 17718496] (b) McMahon CM; Alexanian EJ Angew. Chem., Int. Ed 2014, 53, 5974.(c) Zou Y; Zhou JS Chem. Commun 2014, 50, 3725.(d) Wang G-Z; Shang R; Cheng W-M; Fu Y J. Am. Chem. Soc 2017, 139, 18307. [PubMed: 29116777]

7. (a) Wasa M; Engle KM; Yu J-Q J. Am. Chem. Soc 2010, 132, 3680. [PubMed: 20187642] (b) Stowers KJ; Fortner KC; Sanford MS J. Am. Chem. Soc 2011, 133, 6541. [PubMed: 21476513] (c) He J; Li S; Deng Y; Fu H; Laforteza BN; Spangler JE; Homs A; Yu J-Q Science 2014, 343, 1216. [PubMed: 24626923] (d) Li S; Chen G; Feng C-G; Gong W; Yu J-Q J. Am. Chem. Soc 2014, 136, 5267. [PubMed: 24666182] (e) Jiang H; He J; Liu T; Yu J-Q J. Am. Chem. Soc 2016, 138, 2055. [PubMed: 26796676] (f) Yang W; Ye S; Schmidt Y; Stamos D; Yu J-Q Chem. -Eur. J 2016, 22, 7059. [PubMed: 26991450]

8. (a) Ito C; Itoigawa M; Katsuno S; Omura M; Tokuda H; Nishino H; Furukawa H J. Nat. Prod 2000, 63, 1218. [PubMed: 11000023] (b) Koiso Y; Natori M; Iwasaki S Tetrahedron Lett 1992, 33, 4157.

9. (a) For allylic acetoxylation using sulfoxide ligands, see: Chen MS; White MC J. Am. Chem. Soc 2004, 126, 1346. [PubMed: 14759185] (b) For C-H olefination of electron-rich arenes using simple thioether ligands: Gorsline BJ; Wang L; Ren P; Carrow BP J. Am. Chem. Soc 2017, 139, 9605. [PubMed: 28621936]

10). Pueyo Palazón C; Alfón J; Gaffney P; Berrozpe M; Royo T; Badimon L Atherosclerosis 1998, 136, 333. [PubMed: 9543105]

11. (a) Cornella J; Edwards JT; Qin T; Kawamura S; Wang J; Pan C-M; Gianatassio R; Schmidt M; Eastgate MD; Baran PS J. Am. Chem. Soc 2016, 138, 2174. [PubMed: 26835704] (b) Qin T; Cornella J; Li C; Malins LR; Edwards JT; Kawamura S; Maxwell BD; Eastgate MD; Baran PS Science 2016,352, 801. [PubMed: 27103669] 


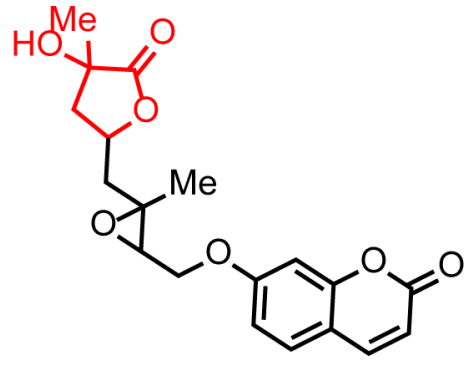

Excavatin M

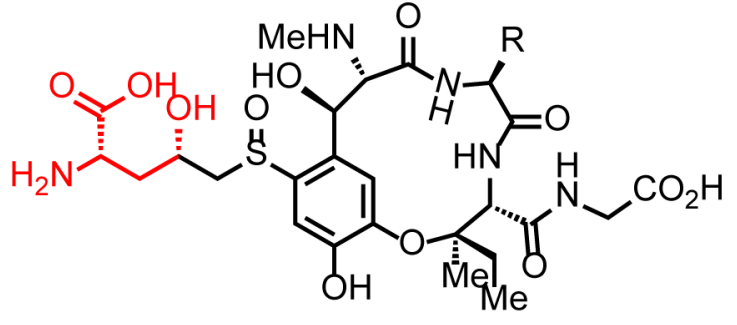

Ustiloxin A R $=\mathrm{CH}\left(\mathrm{CH}_{3}\right)_{2}$

Ustilocin B R $=\mathrm{CH}_{3}$

Figure 1.

Bioactive Compounds Containing $\gamma$-Lactone and Derivatives 


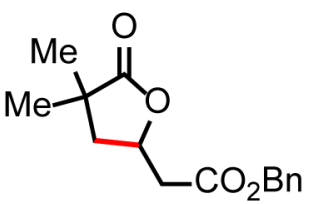

3a, $2.92 \mathrm{~g}, 93 \%^{a}$

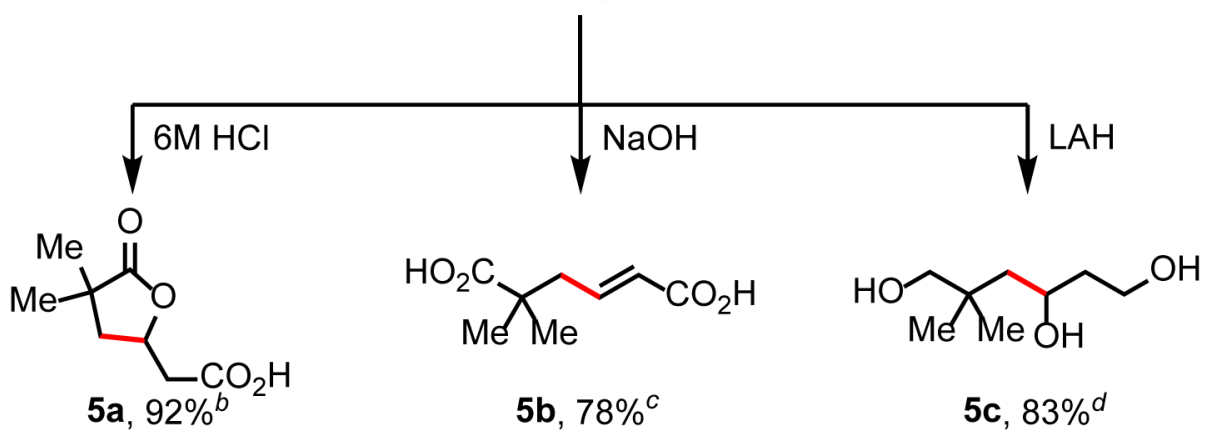

Scheme 1. Gram-Scale Experiment and Synthetic Application

${ }^{a}$ Conditions A: 1a (12.0 mmol), 2a (2.0 eq), Pd(TFA) 2 (10 mol\%), L14 (10 mol\%),

$\mathrm{Na}_{2} \mathrm{HPO}_{4} \cdot 7 \mathrm{H}_{2} \mathrm{O}$ (1.0 eq), $\mathrm{Ag}_{2} \mathrm{CO}_{3}$ (1.0 eq), HFIP, $120{ }^{\circ} \mathrm{C}, 12 \mathrm{~h}$.

${ }^{b}$ Conditions B: $3 a(0.2 \mathrm{mmol}), 6 \mathrm{~N} \mathrm{HCl}, 80^{\circ} \mathrm{C}$, overnight.

${ }^{c}$ Conditions $\mathrm{C}: 3 \mathrm{a}$ (1.0 mmol), $\mathrm{NaOH}(4.0 \mathrm{eq}), \mathrm{EtOH} / \mathrm{H}_{2} \mathrm{O}$, reflux.

${ }^{d}$ Conditions D: 3a (0.2 mmol), LAH (4.0 eq), THF, rt. 
Table 1.

Ligand Development for $\beta-\mathrm{C}\left(\mathrm{sp}^{3}\right)-\mathrm{H}$ Olefination ${ }^{a, b}$

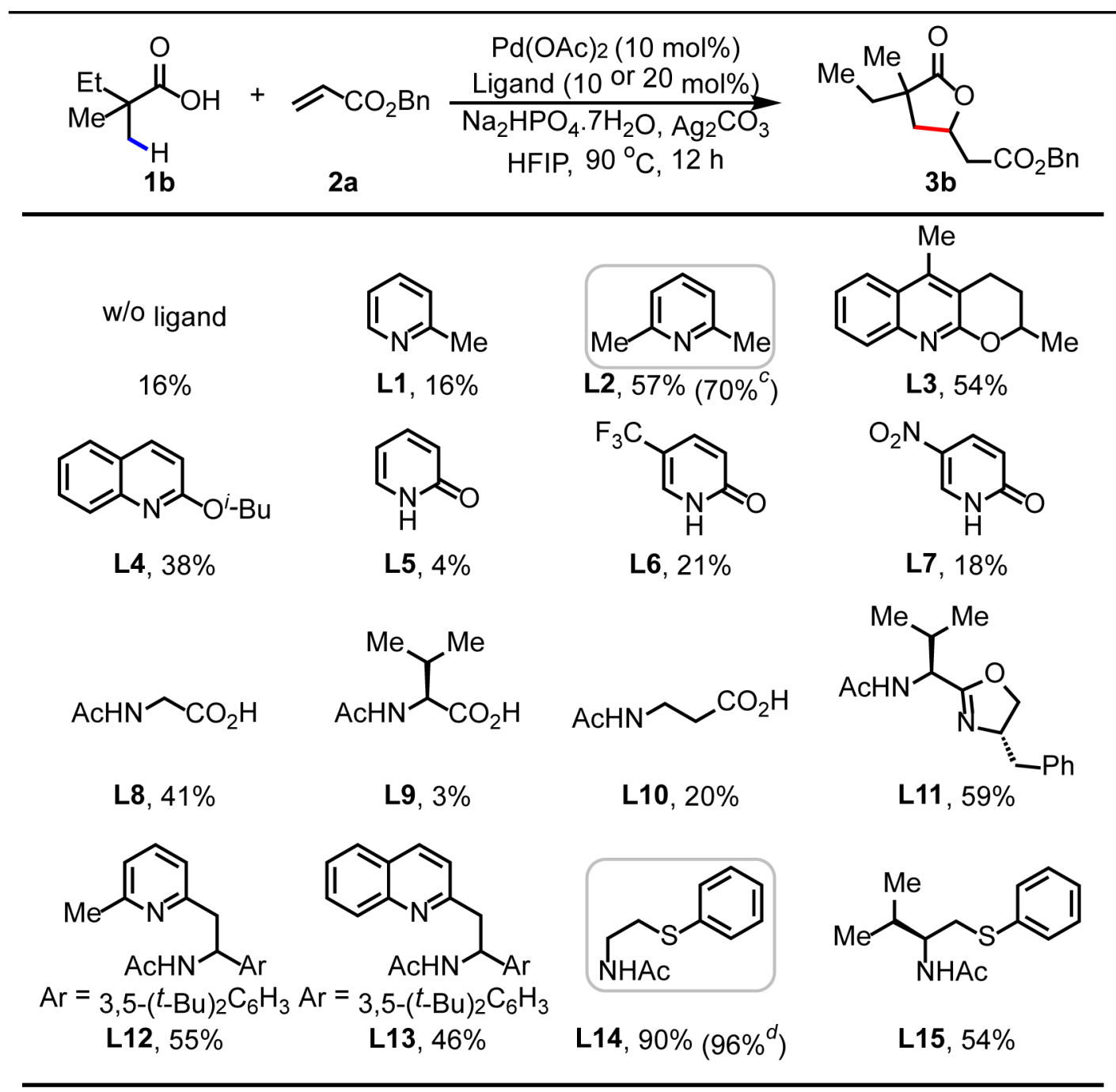

${ }^{a}$ Conditions A: 1b (0.1 mmol), 2a (2.0 eq), Pd(OAc)2 (10 mol\%), ligand (10 mol\% for bidentate ligands (L8-L15) or 20 mol\% for monodentate ligands (L1-L7)), $\mathrm{Na}_{2} \mathrm{HPO}_{4} \cdot 7 \mathrm{H}_{2} \mathrm{O}(1.0 \mathrm{eq}), \mathrm{Ag}_{2} \mathrm{CO}_{3}(1.0 \mathrm{eq}), \mathrm{HFIP}, 90^{\circ} \mathrm{C}, 12 \mathrm{~h}$.

$b_{\text {The yields were determined by }}{ }^{1} \mathrm{H}$ NMR analysis of the crude product using $\mathrm{CH}_{2} \mathrm{Br}_{2}$ as the internal standard.

${ }^{c}$ Conditions B: $1 \mathbf{b}(0.1 \mathrm{mmol}), \mathbf{2 a}(2.0 \mathrm{eq}), \mathrm{Pd}(\mathrm{OAc}) 2$ (10 mol\%), L2 (15 mol\%), $\mathrm{K}_{2} \mathrm{HPO}_{4}(2.0 \mathrm{eq}), \mathrm{Ag}_{2} \mathrm{CO}_{3}(2.0 \mathrm{eq}), \mathrm{HFIP}, 100{ }^{\circ} \mathrm{C}, 24 \mathrm{~h}$. Isolated yield. 
Table 2.

Substrate Scope for $\beta$-C(sp3)-H Olefination ${ }^{a, b}$

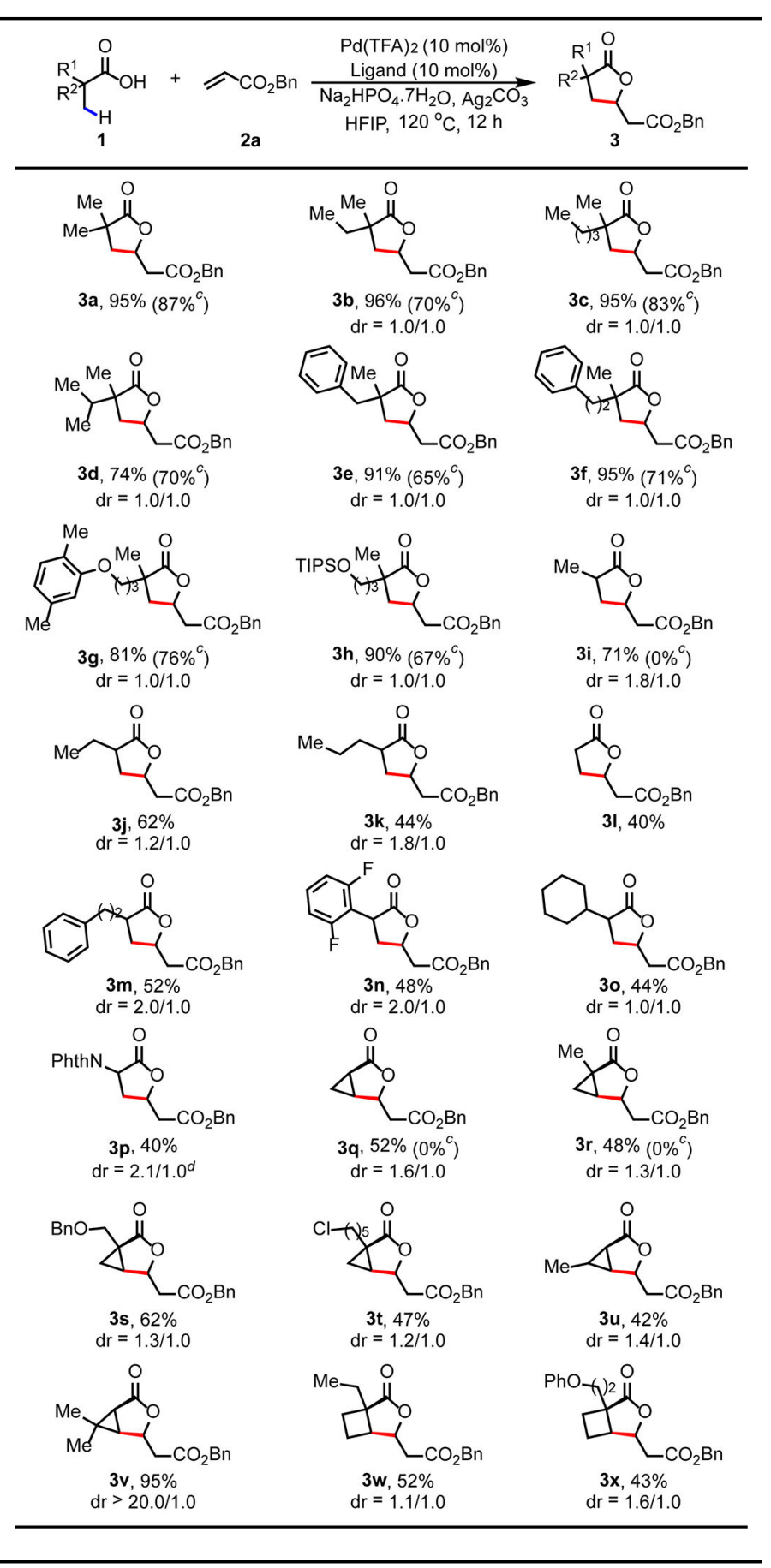

${ }^{a}$ Conditions A: 1 (0.1 mmol), 2a (2.0 eq), Pd(TFA)2 (10 mol\%), L14 (10 mol\%), $\mathrm{Na}_{2} \mathrm{HPO}_{4} \cdot 7 \mathrm{H}_{2} \mathrm{O}(1.0 \mathrm{eq}), \mathrm{Ag}_{2} \mathrm{CO}_{3}$ (1.0 eq), HFIP, $120{ }^{\circ} \mathrm{C}, 12 \mathrm{~h}$. $b_{\text {Isolated yields. }}$ 
${ }^{c}$ Conditions B: 1 (0.1 mmol), 2a (2.0 eq), Pd(OAc) 2 (10 mol\%), L2 (15 mol \%), $\mathrm{K}_{2} \mathrm{HPO}_{4}(2.0 \mathrm{eq}), \mathrm{Ag}_{2} \mathrm{CO}_{3}(2.0 \mathrm{eq}), \mathrm{HFIP}, 100{ }^{\circ} \mathrm{C}, 24 \mathrm{~h}$.

${ }^{d}$ Conditions C: 1p (0.1 mmol), 2a (2.0 eq), Pd(OAc)2 (10 mol\%), L12 (10 mol\%), CsOAc (1.0 eq), $\mathrm{Ag}_{2} \mathrm{CO}_{3}(1.0 \mathrm{eq}), \mathrm{HFIP}, 100{ }^{\circ} \mathrm{C}, 24 \mathrm{~h}$. 
Table 3.

Olefin Scope for $\beta$-C(sp3)-H Olefination ${ }^{a, b}$

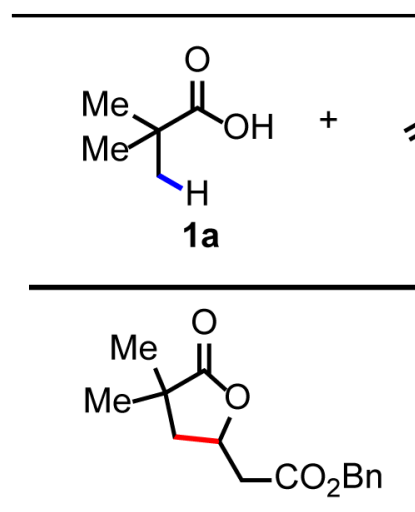

3a, $95 \%$<smiles>CC(C)OC(=O)CC1CC(C)(C)C(=O)O1</smiles>

4c, $91 \%$<smiles>CC1(C)CC(CC#N)OC1=O</smiles>

4f, $78 \%$

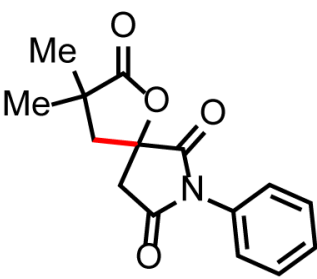

4i, $99 \%^{c}$

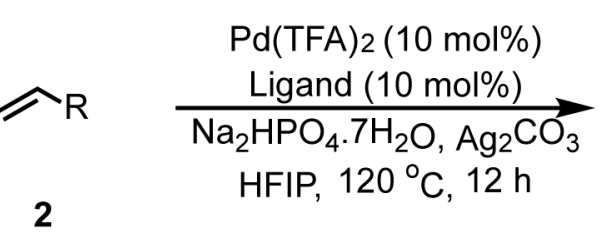

2

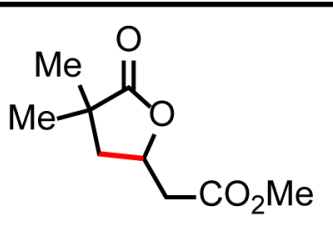

4a, $92 \%$<smiles>CC(=O)CC1CC(C)(C)C(=O)O1</smiles>

4d, $95 \%$<smiles>CC1(C)CC(CS(=O)(=O)c2ccccc2)OC1=O</smiles>

4g, $90 \%$

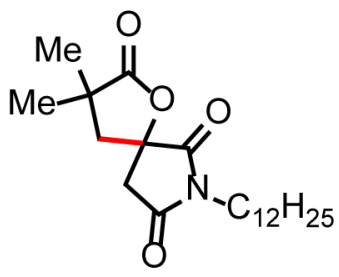

4j, $71 \%^{c}$
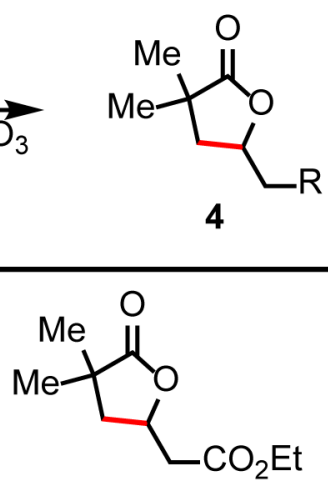

4b, $90 \%$<smiles>CCOCC1CC(C)(C)C(=O)O1</smiles>

4e, $94 \%$

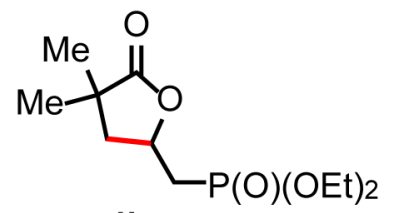

4h, $88 \%$

$\mathbf{4 i}, 99 \%^{c} \quad \mathbf{4 j}, 71 \%^{c} \quad \mathbf{4 k}, 53 \%^{c}(\mathrm{dr}=1.0 / 1.0)$

${ }^{a}$ Conditions A: 1a (0.1 mmol), 2 (2.0 eq), Pd(TFA)2 (10 mol\%), L14 (10 mol\%), $\mathrm{Na}_{2} \mathrm{HPO}_{4} \cdot 7 \mathrm{H}_{2} \mathrm{O}(1.0 \mathrm{eq}), \mathrm{Ag}_{2} \mathrm{CO}_{3}(1.0 \mathrm{eq}), \mathrm{HFIP}, 120^{\circ} \mathrm{C}, 12 \mathrm{~h}$. $b_{\text {Isolated yields. }}$

${ }^{c}$ Conditions B: 1a (0.1 mmol), 2 (2.0 eq), Pd(OAc)2 (10 mol\%), L14 (10 mol\%), $\mathrm{Ag}_{2} \mathrm{CO}_{3}(1.0 \mathrm{eq}), \mathrm{HFIP}, 120{ }^{\circ} \mathrm{C}, 12 \mathrm{~h}$. 